\title{
Role of Occupational Therapy for Schizophrenia
}

\author{
M.Ramakrishnan M.O.T, \\ Occupational Therapist, Department of Psychiatry, JIPMER Hospital, Puducherry-4.
}

\begin{abstract}
A descriptive case study illustrates the experience of 42 years old male with Schizophrenia, with various clinical features are rehabilitated by the Occupational Therapist using therapy methods and techniques on the basis of both in patient and out patient. The plan for the therapy is to motivate the person to engage in typing and improve his functional skills and make him to independent in all areas. After the intervention the improvement seen in the self-care, work and leisure.
\end{abstract}

\section{Introduction}

Occupational Therapy is the branch of medicine and it is very important and crucial as it makes patient independent in activities of daily living. In acute and chronic settings other rehabilitation team members can help in recovery of the patient. Schizophrenia is characterized by disturbance in thought and verbal behavior, perception, affect, motor behavior and relationship to the external world. Hallucinations (perceptions without stimuli) are common in schizophrenia Auditory hallucinations are by far the most frequent. Only the 'third person hallucinations' are believed to be characteristic of Schizophernia ${ }^{1}$. Breier and Strauss conducted a study in which 20 persons hospitalized for psychotic disorders were given semi-structured interviews with the purpose of assessing the ability to self-control psychotic symptoms ${ }^{3}$."Subjects described three major kinds of special control mechanisms: self-instruction, decreased involvement in activity, and increased involvement in activity" (p.1143). Their conclusion is that self-control measures, although not always effective, do have a significant role to play in management of psychotic disorders and deserve further study. A case study conducted by Fisher and Winkler also supports the value of self-control measures, but credits success of these techniques to the subject's belief in their effectiveness ${ }^{4}$. The Occupational Therapy is more likely to focus on the disruption of occupational performance areas of work, leisure and self-care rather than on specific symptoms ${ }^{5}$. Here I describe how Occupational therapy plays an important role in rehabilitation the schizophrenia individual in Indian settings and also share my experience in managing case of schizophrenia in the inpatient and outpatient basis.

\section{Case description}

This descriptive case study illustrates the experience of a 42 years old male with Schizophrenia, clinical features of highly irritable mood, restlessness, hallucination, fearfulness, sleep disturbance, poor self-care and poor socio occupational functioning and excessive use of tobacco. He was married but separated. He had studied up to tenth standard, unemployed. No aggressive behavior. During current illness he has self-care neglect, increased psychomotor activity, talkative, poor attention and concentration, decreased sleeplessness and loss of appetite. He had no previous medical and surgical complaints present. Personnel history during schooling only few friends and regular in schooling, no substance use, alcohol habit, no aggressive behavior present. Socio occupational functioning is moderate. After marriage he did not have children and separated from his wife and he was previously admitted to the psychiatry home at Chennai for treatment of nicotine abuse.

On observation General appearance moderately thin build, Self-care moderate in groomed and dressed, not shaving properly, psychomotor hyperactivity, Social smile present

On examination Sadness of mood was present. Cognitive skills patient is consciously oriented well, able to attend the task and listen to the therapist, memory is fair; no sustaining of attention, no organization and planning skills, no problem solving skills, frustration tolerance is fair during the task. Factors affecting the occupational functioning's highly irritable mood, restless, not following the instructions. Emotional Identification of feeling, anger outbursts, poor self-confidence and self-esteem. Work behavior (type writing, paper envelope) No punctuality and regularity, responsibility of work present like replacing the materials safe, no teamwork, and no neatness of work. Communication skills present initiate conversation like says good morning, thanks. Roles and routines were not presented.

Problem identification wandering tendency is present, poor self-care, poor occupational performance, poor social interaction, poor concentration, and poor self-concepts.

Short term goals Improve concentration, improve self-care.

Long term goals Improve social interaction, improve self-concepts, and improve occupation through motivating him by giving Behavior Modify Intervention (BMI) and Model of Human Occupation (MOHO). 
Occupational Therapy management initially, on giving activities he refused to do them saying he was not capable of doing anything. The therapist encouraged and supported him and gradually he started participating in some of the activities but could not complete even simple tasks that he should have been able to do. Build the rapport with the patient, used a MOHO for getting motivate to do the simple task, behavioral therapy for changing his habit of nicotine substance, talkative, inappropriate behavior (with others in the ward like introducing himself as a patient and I am divorced). Hallucinations decreased while he was participating in certain activities such as playing simple games with therapist. He was suggested that he engage in deep breathing exercises as the hallucinations began which reduced the hallucinations. For this patient's attempts to use sleep (decreased stimulation) to escape the hallucinations were only partially successful.

Use moan (speak softly) for co-operation in doing a task/work. He is interested only in the playing chess and carrom. No outdoor game. Activity scheduling was done after initial assessment of the case which already been in restlessness and not following instruction. In acitivity scheduling self- care activities, tasks and games included which was sit and do with the patient. In between the therapy sessions the coping strategies also be taught to the patient.

\section{Discussion}

Observation in the ward he seemed to be hyperactive before the medication adjustment period was over. Psychotherapeutic intervention given to the patient. After the acute phase around one month restlessness reduced, was very co-operative, reduced sleeplessness, irritable mood, hallucination. Apart from the medical management after ten days following things were observed and he improved in self-care activities like taking bath himself, combing hair, sharing self, dressing properly, washing his cloth, diverting his mind into engaging in the indoor games from the bed. Slowly getting involvement in the typewriting work at least one page with minimal supervision around 20-25 minutes. Reduced the talkativeness due to engaging in games and work. Therapist always used soft voice for co-operation with the activity scheduling and also used the Jacobsen technique which is one of the stress management techniques for getting full relaxation of his mind. Now he is asking about the time scheduling in Tamil version and its purpose. After his discharge he followed up in OPD for continuing of his medication and he continued to maintain his improvement.

\section{Conclusion}

In chronic psychiatric patient apart from medicine Occupational therapy helps in achieve Activities of Daily Living independently and improved social behavior.

[1]. A short Textbook of psychiatry. Niraj Ahuja $7^{\text {th }}$ edition.

[2]. Occupational therapy and physical dysfunction: principles, skills, and practice By Ann Turner, Margaret Foster, Sybil E. Johnson 2002.

[3]. Breier V. \& Strauss J. Self-control in psychotic disorders. Archives of General Psychiatry 1983; 40: 1141-1145.

[4]. Fisher E.B. \& Winkler R. Self-control over intrusive experiences. Journal of Consulting and Clinical Psychology 1975; 6:11-916.

[5]. Rogers J. Order and disorder in medicine and occupational therapy. American Journal of Occupational Therapy 1982; 36:29-35.

[6]. Falloon I. \& Talbot R. Persistent auditory hallucinations: coping mechanisms and implications of management. Psychological Medicine 1992; 198(11): 329-339.

[7]. Honatory G., Goldberg S., Schooler N., \& Ulrich R. Drugs and sociotherapy in the aftercare of schizophrenic patients. Archive s of General Psychiatry 1974; 3: 603-608.

[8]. Wallace C., Nelson C., Liberman R., Lukoff D., Elder J., \& Ferris C. A review and critique of social skill training with schizophrenic patients. Schizophrenia Bulletin 1980; 6(1): 42-63.

[9]. Willard \& Spackman (1993) eight edition Willard \& Spackman's Occupational Therapy.

[10]. Trombly, Catherine A. Occupational Therapy for the Physical Dysfunction $4^{\text {th }}$ edition. 